\title{
The Tangential Force Affecting the Radial Baffles in a Stirred Vessel: Analysis of the Macro-instability Related Component
}

\author{
P. Hasal, I. Fořt, J. Kratěna
}

Experimental data obtained by measuring the tangential component of the force affecting radial baffles in a flat-bottomed cylindrical mixing vessel stirred with a Rushton turbine impeller is analysed. Spectral analysis of the experimental data demonstrated the presence of its macro-instability (MI) related low-frequency component embedded in the total force. Two distinct dimensionless frequencies (both directly proportional to the impeller speed of rotation $N$ ) of the occurrence of the MI component were detected: a lower frequency of approximately $0.025 \mathrm{~N}$ and a higher frequency of about $0.085 \mathrm{~N}$. The relative magnitude $Q_{M I}$ of the MI-related component of the total tangential force was evaluated by a combination of proper orthogonal decomposition (POD) and spectral analysis. The values of magnitude $Q_{M I}$ varied in the interval from approximately 0.05 to 0.30 . The magnitude $Q_{M I}$ takes maximum values at low Reynolds number values (in laminar and transitional regions). In the turbulent region $\left(R e_{M}>20000\right)$ the $Q_{M I}$ value is low and practically constant. The dependence of the $Q_{M I}$ values on vertical position in the vessel is only marginal. The results suggest that the magnitude of the MI component of the force is significantly influenced by the liquid viscosity and density.

Keywords: stirred vessel, baffles, tangential force, macro-instability, spectral analysis, proper orthogonal decomposition.

\section{Notation}

$a(t) \quad$ POD eigenmode [-]

$b \quad$ baffle width [m]

$B \quad$ moving target width [m]

C impeller off-bottom clearance [m]

$D \quad$ impeller diameter [m]

$f_{\mathrm{MI}} \quad$ frequency of macro-instability $\left[\mathrm{s}^{-1}\right]$

$F \quad$ tangential force affecting baffles $[\mathrm{N}]$

$F^{*} \quad$ dimensionless tangential force affecting baffles [-]

$h \quad$ impeller blade width [m]

$h_{\mathrm{T}} \quad$ moving target height [m]

$H \quad$ liquid filling height [m]

$H_{\mathrm{T}} \quad$ moving target axial position [m]

$N \quad$ frequency of impeller revolution $\left[\mathrm{s}^{-1}\right]$

$N_{\text {B }} \quad$ number of impeller blades [-]

$N_{\mathrm{S}} \quad$ number of samples [-]

$Q_{\mathrm{MI}}$ relative magnitude of MI-related fraction of tangential force [-]

R autocovariance matrix [-]

$\operatorname{Re}_{M}$ impeller Reynolds number, $\operatorname{Re}_{M}=\left(\rho N D^{2}\right) / \eta[-]$

$s_{\mathrm{MI}}^{2} \quad$ variance of the $\mathrm{MI}$ component of the dimensionless force [-]

$s_{\text {tot }}^{2} \quad$ variance of the total dimensionless force [-]

$s_{\mathrm{n}-\mathrm{MI}}^{2}$ variance of the non-MI components of the dimensionless force [-]

$t \quad$ time [s]

$T \quad$ mixing vessel diameter $[\mathrm{m}]$
$T_{\mathrm{S}} \quad$ sampling period $[\mathrm{s}]$

V POD eigenvectors [-]

$\mathrm{W}$ trajectory matrix [N]

$\alpha \quad$ POD eigenvalue [-]

$\rho \quad$ liquid density $\left[\mathrm{kg} \mathrm{m}^{-3}\right]$

$\eta \quad$ dynamic liquid viscosity $[\mathrm{Pas}]$

Abbreviations:

CFD computational fluid dynamics

GC cold glycerol solution

$\mathrm{GH}$ hot glycerol solution

MI macro-instability

PBI pitched blade impeller

POD proper orthogonal decomposition

WA water

\section{Introduction}

The liquid flow in mechanically stirred vessels has been studied intensively in recent decades. Numerous theoretical and experimental studies have been performed concerning various aspects of liquid flow in stirred vessels, e.g., the mean flow velocity, the intensity of turbulence, the energy dissipation rate, spatial and temporal scales of the turbulent velocity field, etc. The liquid flow in a stirred vessel operated under steady operational conditions may be considered as a pseudo-stationary high-dimensional dynamical system constituted by hierarchically ordered unsteady flows (vortices and eddies). The temporal and spatial scales of these flows span several decimal orders of magnitude. Recently, a pseudo-periodic large-scale flow has been identified in stirred vessels 
occurring with very low frequency and manifesting itself on spatial scales comparable to the size of the mixing vessel [1-8]. This flow was named the macro-instability (MI) of the flow pattern, and its existence has been confirmed by a special mechanical measuring device [6], by laser-Doppler velocimetry (LDV) [7], and by image analysis methods [8]. The presence of the MI in the flow pattern is typically displayed by a distinct peak in the low-frequency part of the power spectrum of the local liquid velocity or other liquid flow-related experimental data. Comprehensive reviews of a broad spectrum of the experimentally observed phenomena related to the macro-instability were given in our previous papers [6, 7, 9-13]. The macro-instability of the flow pattern yields strong impacts on mixing processes closely linked to fluid motion, e.g., on local mass- and heat-transport rates, local gas hold-up, the homogenisation rate, etc. [3, 5]. Bittorf and Kresta [14] identified the macro-instability of the flow pattern as a mechanism responsible for liquid mixing outside the active volume of the primary liquid circulation loop. Although the existence of the macro-instability of the flow pattern in stirred vessels has been proved many times in experiments and CFD simulations its origin and development is not completely clear yet. Three possible reasons of the existence of the MI in stirred vessels with a Rushton turbine impeller have been hypothesised in the literature [15-17]: the first kind of instability is associated with variations in the impeller off-bottom clearance. Montante et al [16] reported a variation in the flow at different clearances from the vessel bottom. The radial flow pattern was observed at high off-bottom clearances $(C>0.2 T)$ whilst the axial pattern was observed at $C<0.15 T$. Intermittent switching between axial and radial flow was detected at $0.15 T<C<0.2 T$. The changes in the flow pattern in the unstable cases occurred over time scales of the order of $10 \mathrm{~min}$. The second kind of flow pattern instability is related to variations in the impeller rotational speed, when the flow pattern switches from mainly radial to mainly axial at a certain (critical) impeller speed (or $R_{M}$ ) value. The third kind of macro-instability arises from a "whirlpool" type of vortex (or coupled vortices) moving around the mixing vessel axis with the frequency of around $2 \%$ of the impeller frequency $N$ (see Nikiforaki et al [17]).

The origin and the development of the MI of the flow pattern in the mixing vessels with the PBI was described by Brůha et al [6] and by Montes et al [7], who visually detected an axial flow originating in a pseudo-periodic manner at the vessel bottom and ascending along the baffle towards the liquid surface.

The frequency of the occurrence of the macro-instability in all experiments reported in the literature [e.g., 6, 7, 9-11, 17] was directly proportional to the frequency of the impeller rotation. However, considerable scatter of the proportionality constant values (the dimensionless MI frequency) is apparent from the published data. Nikiforaki et al [17] have explained a part of this scatter by inadequacies in the experimental data treatment and interpretation methods adopted by different authors. However, it is evident from the published data that at least two different macro-instability frequencies, corresponding to different mechanisms of $\mathrm{MI}$ origin, exist in the mixing vessels stirred with a Rushton turbine. Nikiforaki et al [17] observed that higher MI frequency (about $10 \%$ of $N$ ) occurs at low impeller Reynolds number values, and that the lower frequency (about $2 \%$ of $N$ ) prevails at high $\operatorname{Re}_{\mathrm{M}}$. Both frequencies were simultaneously present in the power spectra of the data measured at medium $\operatorname{Re}_{\mathrm{M}}$ values. The lower frequency was assigned to intermittent switching between the single- and the double-loop flow pattern, while the higher frequency was assigned to precessional vortex motions.

The macro-instability of the flow-pattern also exerts strong forces affecting the solid surfaces immersed in the stirred liquid, for example on the baffles, the draft tubes, the cooling and heating coils, etc. [12]. These forces may significantly affect the performance of the mixing vessel and, in certain cases, can even cause serious failures of the mixing equipment.

An axially located impeller in a standard cylindrical mixing vessel equipped with radial baffles exhibits, in general, three force effects: axial, radial and tangential. The axial and the radial forces only slightly affect the radial baffles. Conversely, it is the tangential force that exhibits the most of the dynamic pressure affecting them. The vertical distribution (along the baffle) of the tangential force in a standard mixing vessel was measured by Kratěna et al $[12,13]$ over a wide interval of the impeller Reynolds number value and in dependence on the impeller off-bottom clearance. Two kinds of the impeller were used: the pitched blade impeller with four or six blades, and a standard Rushton turbine. The pitched blade impellers elicited maximum force at the vessel bottom, and the magnitude of the force gradually decayed in the direction towards the liquid level. The Rushton turbine impellers yielded the maximum force at the impeller level, and the force rapidly vanished in both the below-impeller and the above-impeller region.

Few attempts have been reported in the literature $[18,19]$ to separate the deterministic (low frequency and MI-related) and the stochastic (turbulent) components of mixing phenomena in stirred tanks. Letellier et al [18] adopted a Hilbert transform-based procedure for separating the low-dimensional deterministic part of the experimental time series. Kovacs et al [19] used the Fourier transform for the same purpose. Recently we have established a new technique (based on a combination of spectral analysis and proper orthogonal decomposition) for detecting the macro-instability of the flow pattern from the local velocity data, evaluating its relative magnitude and reconstructing its temporal evolution [9-11].

In this paper we apply this technique to the experimental data obtained by Kratěna et al $[12,13]$ by measuring the tangential component of the force exerted on the radial baffles in the mixing vessel with a standard Rushton turbine impeller in order to identify and quantify its macro-instability related component. We also analyse the vertical distribution of the MI component in the vessel and the effects of the frequency of the impeller revolution and of the liquid viscosity on its magnitude. The frequency of occurrence of the macro-instability related force component is also analysed.

\section{Experimental}

A cylindrical flat-bottomed vessel with four radial baffles was used in all experiments reported in this paper. The dimensions of the vessel and of the Rushton turbine impeller are marked in Fig. 1 and their values are listed in Table 1. Water (WA) and hot (GH) and cold (GC) aqueous glycerine 
Table 1: Dimensions of the mixing vessel and the impeller

\begin{tabular}{|l|l|}
\hline Dimension & Value \\
\hline Vessel diameter & $T=0.3 \mathrm{~m}$ \\
\hline Liquid aspect ratio & $H / T=1$ \\
\hline Impeller to tank diameter ratio & $D / T=0.333$ \\
\hline Relative impeller off-bottom clearance & $C / T=0.35$ and 0.50 \\
\hline Measuring target relative axial position & $H_{\mathrm{T}} / H=0 ; 0.1 ; 0.2 ; 0.27 ; 0.35 ; 0.42 ; 0.5 ; 0.57 ; 0.65 ; 0.8 ; 0.92$ \\
\hline Relative baffle width & $b / T=0.1$ \\
\hline Relative impeller blade height & $w / D=0.2$ \\
\hline Relative impeller blade width & $l / D=0.25$ \\
\hline Number of impeller blades & $N_{\mathrm{B}}=6$ \\
\hline
\end{tabular}
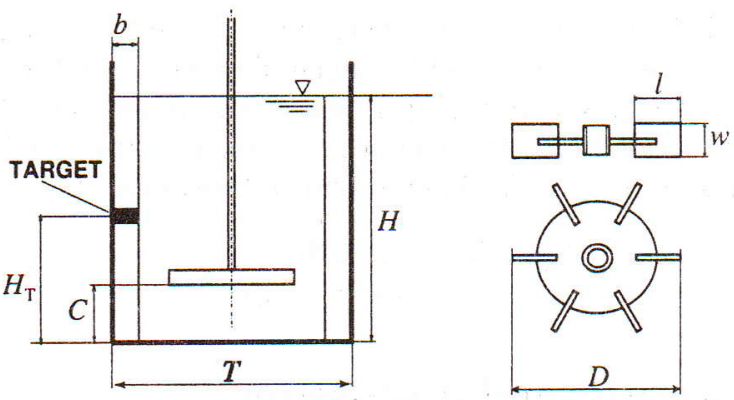

Fig. 1: The mixing vessel and the impeller geometry. The label TGT indicates the moving target positioned in the baffle slit.

solutions (viscosity 3 and $6 \mathrm{mPas}$, respectively) were used as working liquids. The frequency of impeller rotation $N$ was varied from $3.17 \mathrm{~s}^{-1}$ to $6.0 \mathrm{~s}^{-1}$. The corresponding interval of $\operatorname{Re}_{M}$ values (approximately from 6000 to 60000) covers the laminar, transition and turbulent regions.

The tangential force affecting the baffles was measured by means of a trailing target (target height $h_{\mathrm{T}}=10 \mathrm{~mm}$, target width $\mathrm{B}=28 \mathrm{~mm}$ ) located in a slit made in the baffle and enabled to rotate around an axis parallel to the vessel axis. The target was balanced by a couple of (calibrated) springs, and its angular displacement was scanned via a photo-electronic sensor (see Kratěna et al $[12,13]$ for details of the measuring equipment). The sampling period was $T_{\mathrm{S}}=20 \mathrm{~ms}$. The signal from the sensor was recorded on a PC (after $\mathrm{A} / \mathrm{D}$ conversion) and subsequently used for evaluation of the tangential force affecting the target. The duration of a single experiment was 20 minutes and $N_{\mathrm{S}} \approx 60000$ samples were typically stored. The local force measured at the target position was converted to a dimensionless force according to the relation

$$
F^{*}=\frac{F}{\rho N^{2} D^{4}}
$$

The time series of the dimensionless force at distinct locations $H_{\mathrm{T}} / H$ of the target along the baffle (see Table 1) were used for detection and analysis of the macro-instability related component of the total force. At each target position and relative impeller off-bottom clearance $\mathrm{C} / \mathrm{H}$, the value of $\mathrm{Re}_{\mathrm{M}}$ was varied over the entire attainable interval. The total number of processed data sets was 310 .

\section{Numerical analysis of experimental data}

The numerical procedures used for experimental data analysis are here described only in basic features, as details can be found either in our previous reports [9-11] or in the original papers [20, 21].

The power spectra of the time records of the measured tangential force were used to detect the presence of its low-frequency component(s) generated by the macro-instability of the flow pattern. The power spectral densities were evaluated by means of an algorithm based on the fast Fourier transform.

A procedure based on an application of the proper orthogonal decomposition (POD) technique was used for extracting the MI-related low-frequency component from the experimental data. First, the raw data is centred by subtracting the mean force value. Then, by application of the so-called $N$-window [21] to the data and after some algebraic manipulations the so-called trajectory matrix $\mathbf{W}$ is obtained. Then, the auto-covariance matrix $\mathbf{R}$ of the trajectory matrix $\mathrm{W}$ is then evaluated by matrix multiplication

$$
\mathbf{R}=\mathbf{W} \mathbf{W}^{\mathrm{T}}
$$

and its (non-negative) eigenvalues $\alpha_{k}$ and eigenvectors $\mathbf{V}_{k}$ $(k=1, \ldots, N)$ are determined. The eigenvalues, sorted in decreasing order, form the spectrum of POD eigenvalues and each ak expresses the magnitude of the contribution of the $k$-th eigenmode to the total force. The eigenvectors $\mathbf{V}_{k}$ are used for evaluating the eigenmodes $a_{k}(t)$ of the measured data [10]. Then, the power spectra of the eigenmodes $a_{k}(t)$ are evaluated and the only eigenmodes with significant peaks in their power spectra, located exactly at the macro-instability frequency (or frequencies), are used for evaluating the relative magnitude $Q_{\mathrm{MI}}$ of the macro-instability related compo- 

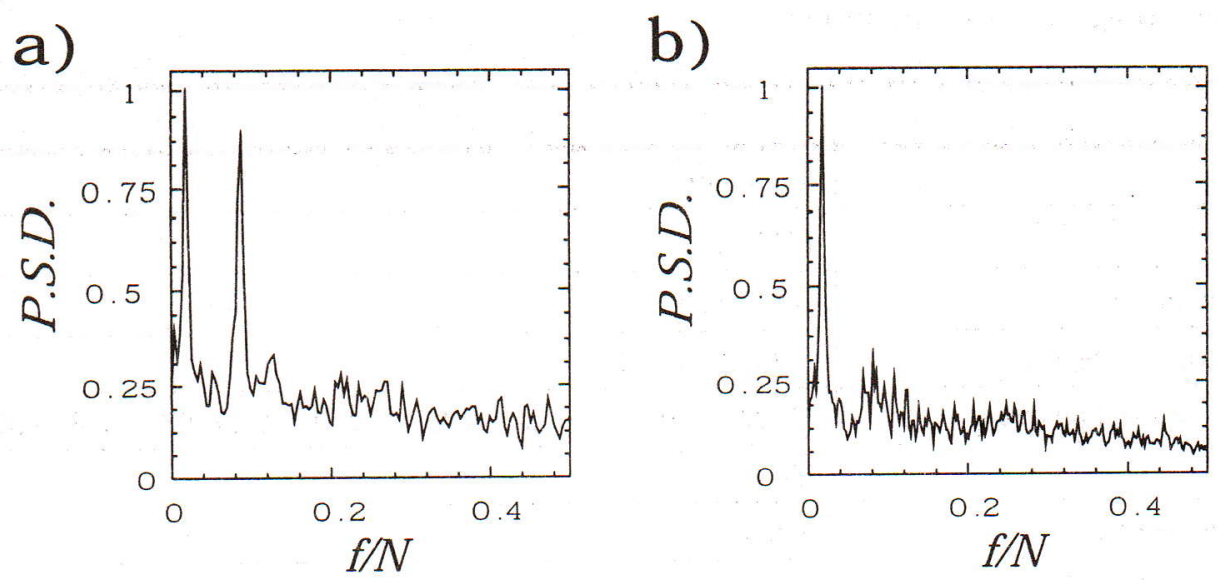

Fig. 2: The normalised power spectral densities of the measured tangential force affecting the baffle. a) $C / H=0.35, H_{\mathrm{T}} / H=0.50$, $\left.N=3.333 \mathrm{~s}^{-1}, \operatorname{Re}_{\mathrm{M}}=9095 ; \mathbf{b}\right) C / H=0.35, H_{\mathrm{T}} / H=0.50, N=6.0 \mathrm{~s}^{-1}, \operatorname{Re}_{\mathrm{M}}=15889$.

nent of the total force affecting the baffles according to the relation

$$
Q_{M I}=\frac{\sum_{j \in K_{M I}} \alpha_{j}}{\sum_{j=1}^{N} \alpha_{j}},
$$

where $K_{\mathrm{MI}}$ is the set of indices of the eigenmodes contributing to the macro-instability. When two MI frequencies (cf. Fig. 2) were present in the analysed data all POD eigenmodes contributing to both of them were included in the $K_{\mathrm{MI}}$ set in Eq. (3), i.e., the total macro-instability related component of the force affecting the baffle was evaluated. The POD eigenmodes very frequently captured simultaneously both MI frequencies, and therefore it was impossible to discriminate between their contributions to either of the individual MI frequencies. Only a rough estimate of the relative proportion of the lower frequency and the higher frequency sub-components of the total MI force component was possible in a few cases (see section Results and Discussion).

a)

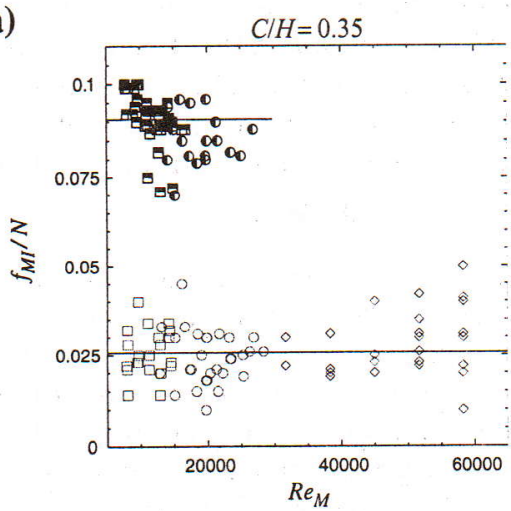

The value of the relative magnitude $Q_{\mathrm{MI}}$ defined by Eq. (3) is expressed by means of the eigenvalues of the POD eigenmodes. $Q_{M I}$ is therefore equal to the value of the ratio of the variance of the MI-related force component to the total force variance, as shown by Lumley [20] or Aubry et al [21]

$$
Q_{\mathrm{MI}}=\frac{s_{\mathrm{MI}}^{2}}{s_{\text {tot }}^{2}}=\frac{s_{\mathrm{MI}}^{2}}{s_{\mathrm{MI}}^{2}+s_{\mathrm{n}-\mathrm{MI}}^{2}} \text {. }
$$

\section{Results and discussion}

There are two primary factors characterising the macro-instability related component of the tangential force affecting the baffles: the frequency (or frequencies) of its occurrence $f_{\mathrm{MI}}$ and its relative magnitude $Q_{\mathrm{MI}}$ (see Eq. 3).

An analysis of the experimental data obtained in the mixing vessel with the pitched blade impeller has shown [11] that the frequency of MI occurrence $f_{\mathrm{MI}}$ is directly proportional to the impeller frequency $N$, i.e., the dimensionless frequency $f_{\mathrm{MI}} / N$ attains a constant value. The proportionality constant (or dimensionless frequency) value was 0.074 . The dimensionless frequency in the case of the PBI was independ-

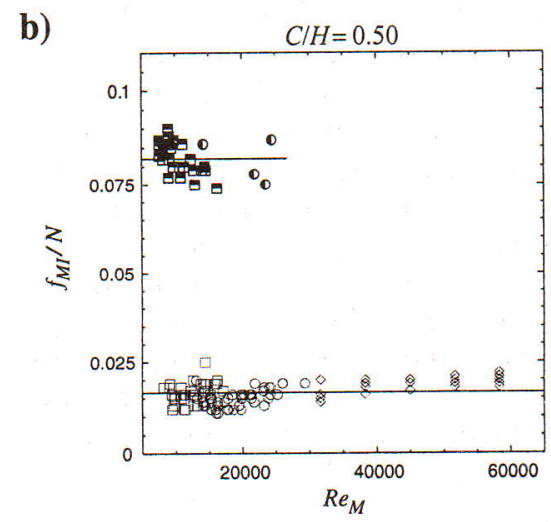

Fig. 3: The dimensionless frequency of the macro-instability component of the tangential force affecting the baffles as a function of the

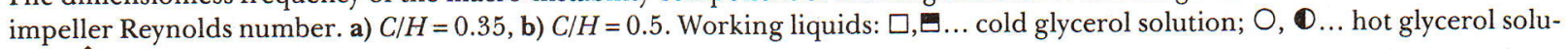
tion; $\diamond \ldots$ water. 
a)

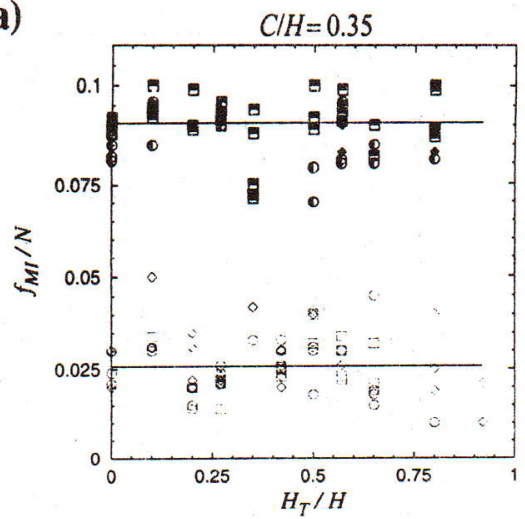

b)

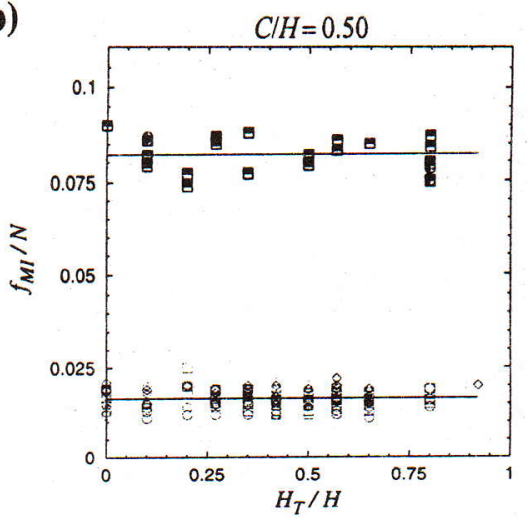

Fig. 4: The dimensionless frequency of the macro-instability component of the tangential force affecting the baffles as a function of the measuring target vertical position. a) $C / H=0.35, \mathbf{b}) C / H=0.5$. Working liquids: $\square, \mathbf{D} \ldots$ cold glycerol solution; $O$, ... hot glycerol solution; $\diamond, \ldots$ water.

ent of the impeller off-bottom clearance $C / T$, of the impeller Reynolds number value, and of the vertical position in the vessel. No effects of liquid viscosity and density on the $f_{\mathrm{MI}}$ value were observed.

Qualitatively distinct behaviour of the macro-instability was observed in the mixing vessel stirred with a Rushton turbine impeller. Two frequencies of a MI occurrence were typically detected in the laminar and transitional regions of liquid flow (see Fig. 2a) and a single MI frequency was typically detected in the turbulent flow region (Fig. 2b). This observation agrees well with the experimental results of Nikiforaki et al [17], and we can conclude that two mechanisms of MI formation were present in the mixing vessel studied in this paper. The lower dimensionless frequency of MI occurrence $f_{\mathrm{MI}}$ varies about 0.02 , and the upper dimensionless frequency value is close to 0.085 . Both frequencies, however, are independent of the $\operatorname{Re}_{\mathrm{M}}$ value and of the position of the measuring target $H_{\mathrm{T}} / H$, as documented in Figs. 3 and 4 . It can be deduced from Figs. 2-4 that the MI occurrence frequency is slightly lower at higher impeller off-bottom clearance, i.e., at $C / H=0.5$. The mean values of the dimensionless frequencies at different vessel configurations are summarised in Table 2. In general, there is considerably higher scatter of the MI frequency data at the lower impeller position $(C / H=0.35)$. The reason for this observation consists probably in the instability of the flow pattern arising due to the asymmetry of the below-impeller and the above-impeller liquid circulation loops and due to their irregular (erratic) interactions.

The vertical distributions of the relative magnitude of the MI-related component of the force affecting the baffles $Q_{M I}$ (evaluated according Eq. 3) are shown in Fig. 5. Generally, higher values of $Q_{\mathrm{Mr}}$ are observed at low $\operatorname{Re}_{\mathrm{M}}$ values and a quite steep decrease is observed at ReM values just below approx. 20000. The $Q_{\mathrm{MI}}$ values are almost constant in the highly turbulent region of liquid flow, despite the impeller off-bottom clearance and vertical position in the vessel. By comparing Figs. $5 \mathrm{a}, \mathrm{c}$ and $5 \mathrm{~b}, \mathrm{~d}$ it is easily recognisable that the dependence of the $Q_{M I}$ value on $\operatorname{Re}_{\mathrm{M}}$ qualitatively differs in the below-impeller and the above-impeller regions: the decrease of the $Q_{\mathrm{MI}}$ value with increasing $\mathrm{Re}_{\mathrm{M}}$ is more pronounced in the above-impeller region. Generally, the magnitude of the MI-related component of the tangential force gains slightly higher values in the above-impeller region at both impeller off-bottom clearances. The range of observed $Q_{\mathrm{MI}}$ values is quite broad, approximately from 0.05 to 0.30 . The low-frequency component of the force affecting the radial baffles thus represents a significant part of the total force, especially at low $\operatorname{Re}_{\mathrm{M}}$ values $\left(\operatorname{Re}_{\mathrm{M}} \leq 20000\right)$. Vertical distributions of the $Q_{\mathrm{MI}}$ value in the vessel are depicted in Fig. 6, where averaged $Q_{\mathrm{MI}}$ values are plotted against $H_{\mathrm{T}} / H$ (for a fixed vertical position and a given working liquid all available $Q_{M I}$ values-differing in corresponding $\mathrm{Re}_{\mathrm{M}}$-were averaged).

Tab. 2: Dimensionless frequencies of the macro-instability generated by a Rushton turbine impeller

\begin{tabular}{|c|c|c|c|}
\hline \multirow{2}{*}{ Impeller off-bottom clearance } & \multirow{2}{*}{ Liquid } & \multicolumn{2}{|c|}{ Dimensionless MI frequency $f_{\mathrm{MI}} / A$} \\
\cline { 2 - 4 } & & lower & upper \\
\hline \multirow{3}{*}{$C / H=0.35$} & GC & $0.0258( \pm 0.0066)$ & $0.0906( \pm 0.0069)$ \\
\cline { 2 - 4 } & GH & $0.0243( \pm 0.0074)$ & $0.0853( \pm 0.0070)$ \\
\cline { 2 - 4 } & WA & $0.0275( \pm 0.0089)$ & $0.0821( \pm 0.0042)$ \\
\hline \multirow{3}{*}{$C / H=0.50$} & GC & $0.0165( \pm 0.0026)$ & $0.0815( \pm 0.0059)$ \\
\cline { 2 - 4 } & GH & $0.0150( \pm 0.0024)$ & - \\
\cline { 2 - 4 } & WA & $0.0184( \pm 0.0020)$ & $0.040)$ \\
\hline
\end{tabular}


a)

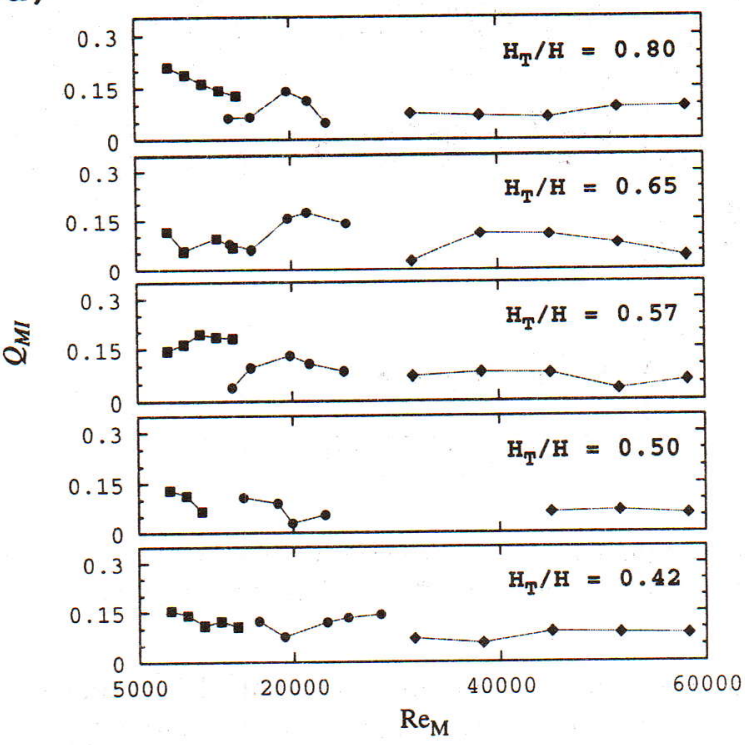

b)

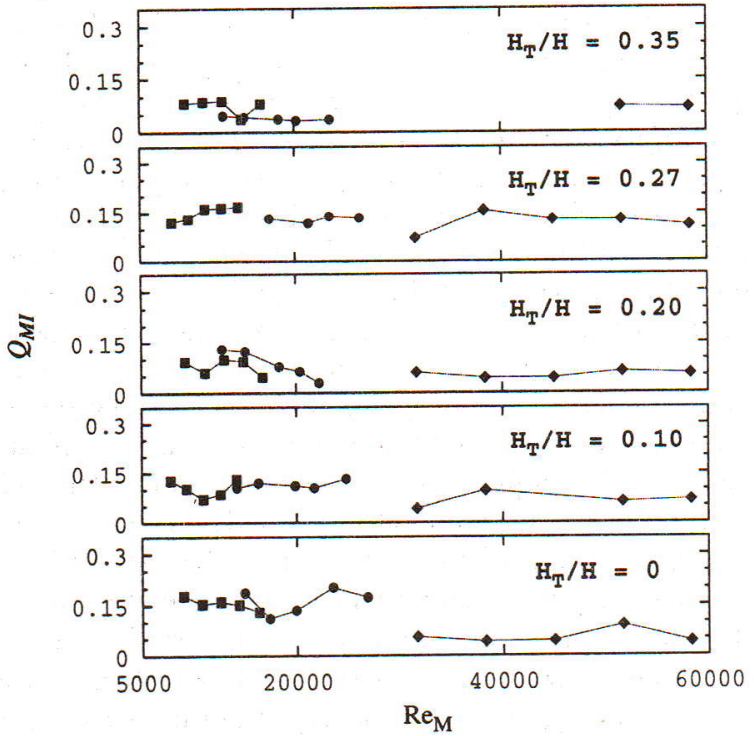

c)

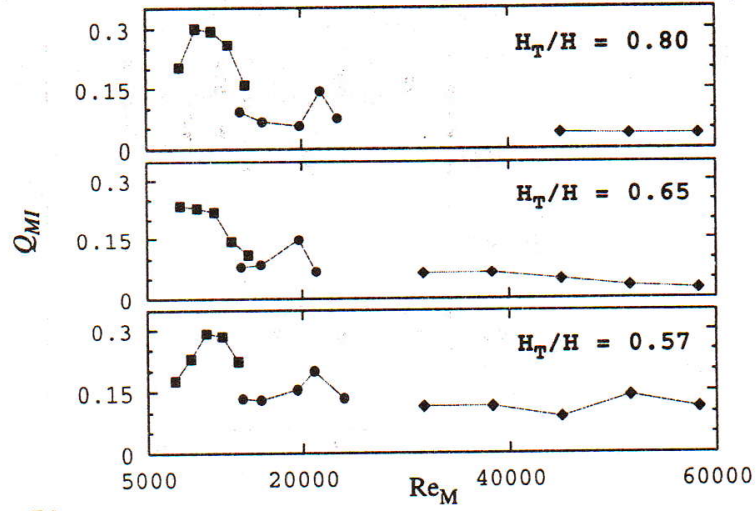

d)
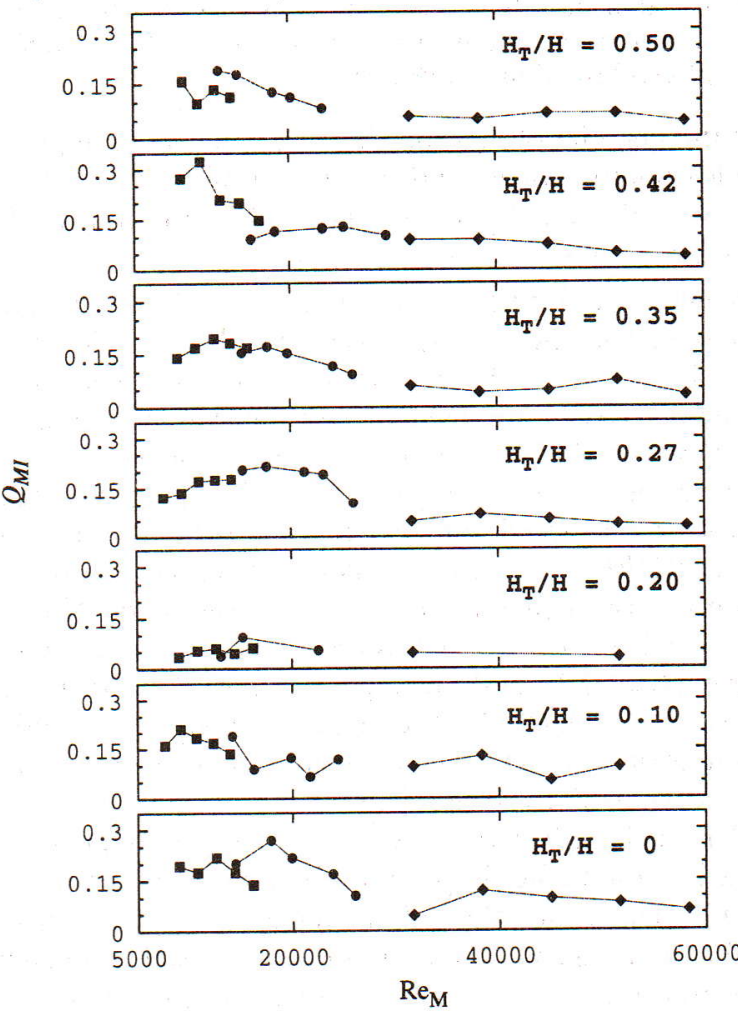

Fig. 5: Relative magnitude of the MI-related component of the tangential force affecting the baffles.

a) $C / H=0.35$ - the above impeller region; b) $C / H=0.35$ - the below impeller region; $\mathbf{c}) C / H=0.50$ - the above impeller region

d) $C / H=0.50$ - the below impeller region. Working liquids:

.. cold glycerol solution; ... hot glycerol solution;

water.

The vertical (axial) profiles of the averaged $Q_{\mathrm{MI}}$ values are quite flat and the $\left\langle Q_{\mathrm{MI}}\right\rangle$ values are not apparently influenced by the impeller off-bottom clearance. $\left\langle Q_{\mathrm{MI}}\right\rangle$ takes its highest values when cold glycerol is used as the working liquid and decreases with decreasing liquid viscosity. However, this trend reflects the fact that the impeller Reynolds number value in creases with decreasing viscosity, so the differences in the $\left\langle Q_{M I}\right\rangle$ values observed in Fig. 6 are primarily due to the increasing $\operatorname{Re}_{M}$ value (cf. Fig. 5).

To elucidate the influence of the impeller off-bottom clearance on the $\left\langle Q_{\mathrm{MI}}\right\rangle$ values and to emphasise the difference between the above- and below-impeller regions, spatially averaged $\left\langle Q_{M I}\right\rangle$ values (at a fixed $\operatorname{Re}_{M}$ value all $Q_{M I}$ 's along the baffle are averaged) are plotted in Fig. 7 against the Reynolds number values. The MI-related component of the force follows the general trend observed in Fig. 5: the maximum $\left\langle Q_{\mathrm{MI}}\right\rangle$ value is observed in the laminar region, then (with the increasing $\operatorname{Re}_{\mathrm{M}}$ ) the $\left\langle Q_{\mathrm{MI}}\right\rangle$ value monotonously falls until it reaches a practically constant value in the region of fully turbulent flow. This trend repeats in all plots in Fig. 7, except for Fig. 7b, where (due to the enhanced data scatter an almost linear spline approximation is used). No effects of liquid viscosity or density on the $\left\langle Q_{\mathrm{MI}}\right\rangle$ values are apparent from Fig. 7.

As we have noted in the section on Numerical analysis of experimental data it is, in general, impossible to distinguish between the contributions of the lower-frequency and 

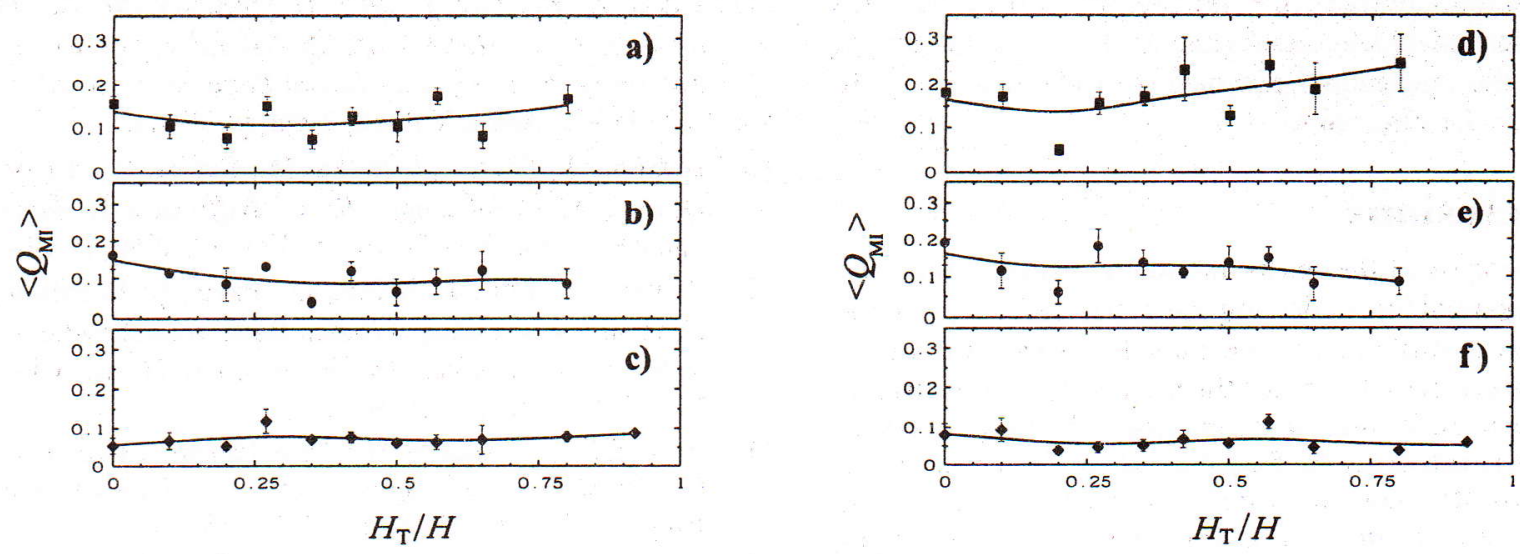

Fig. 6: The vertical distribution of the averaged relative magnitude of the MI-related component $\left\langle Q_{\mathrm{MI}}\right\rangle$ of the tangential force in the vessel. a) $C / H=0.35$, cold glycerol solution (GC, a) ; b) $C / H=0.35$, hot glycerol solution $(\mathrm{GH}, \mathbf{0})$; c) $C / H=0.35$, water (WA, d) $C / H=0.50$, cold glycerol solution (GC, e) $C / H=0.50$, hot glycerol solution $(\mathrm{GH}, 0)$; $\mathrm{f} C / H=0.50$, water (WA, $)$. The errorbars display the interval of \pm 1 S.D. from the mean values.

a)

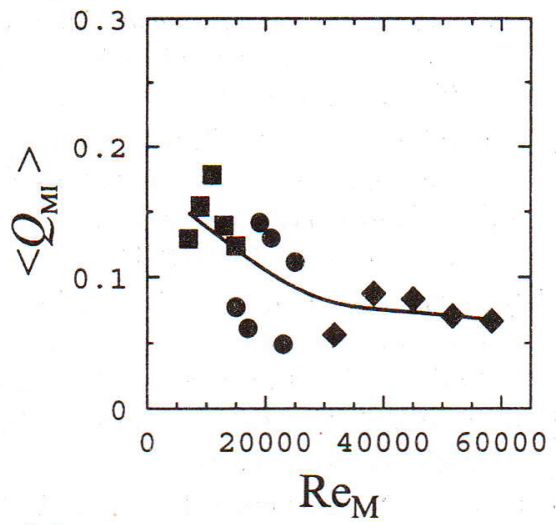

b)

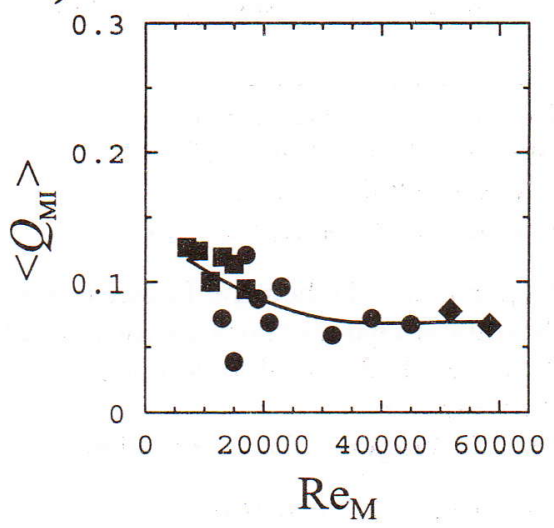

c)

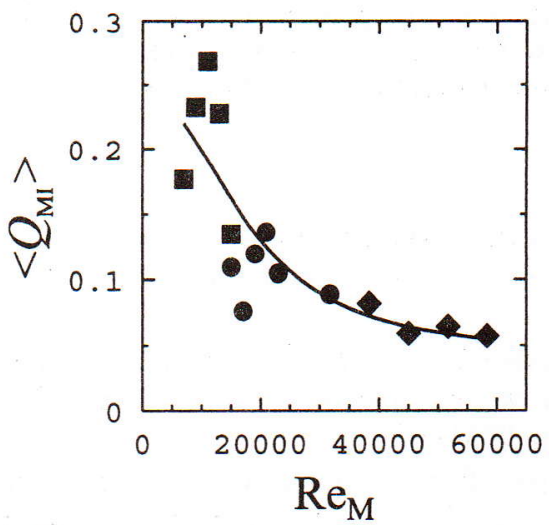

d)

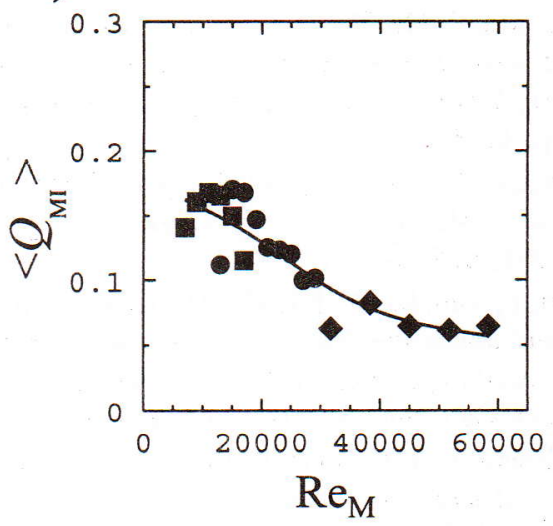

Fig. 7: The averaged magnitude of the MI-related component of the tangential force $\left\langle Q_{\mathrm{Ml}}\right\rangle$ as a function of the impeller Reynolds number. a) $C / H=0.35$, the above impeller region; b) $C / H=0.35$, the below impeller region; c) $C / H=0.50$, the above impeller region; d) $C / H=0.50$, the below impeller region. Working liquids: $\ldots$ cold glycerol solution $(\mathrm{GC}), \ldots$ hot glycerol solution $(\mathrm{GH})$, .... water (WA).

the higher-frequency sub-components to the total MI-related force. Such a dissection was, however, possible for several data sets obtained at the lowest $\operatorname{Re}_{\mathrm{M}}$ values, i.e., with the cold glycerol solution as a working liquid. The ratio of the lower frequency to the upper-frequency sub-component varied from approximately 0.725 to 1.5 , i.e., both sub-components may (although not very significantly) dominate the macro-instability related force acting on the baffles. The limited 
amount of data available for the analysis, however, did not allow of any plausible conclusions to be deducted on the effects of the operational parameters of the vessel and the impeller on the ratio value.

\section{Conclusions}

The analysis of the macro-instability related component of the tangential force affecting the radial baffles in a stirred vessel with a Rushton turbine impeller performed in this paper enables us to determine the frequency of its occurrence and to evaluate its relative magnitude. The frequencies are linearly dependent on the frequency of revolution of the impeller. Two MI frequencies were observed at $\operatorname{Re}_{M}<20000$. The MI-related component of the force constitutes a highly significant contribution to the total force until the mixing is laminar or weakly turbulent. The results of our study agree well with the findings of other authors obtained, however, by analysing experimental data of a qualitatively distinct nature (e.g., liquid velocity components).

\section{Acknowledgment}

Financial support for this project by the Ministry of Education of the Czech Republic is gratefully acknowledged (Projects: MSM223400007 and J04/98:212200008).

\section{References}

[1] Bakker, A., Van den Akker, H. E. A.: Single-phase Flow in Stirred Reactors. Trans. IChemE, Vol. 72A, 1994, p. 583-593.

[2] Chapple, D., Kresta, S.: The Effect of Geometry on the Stability of Flow Patterms in Stirred Tanks. Chem. Eng. Sci., Vol. 21, 1994, p. 3651-3660.

[3] Haam, S., Brodkey, R. S., Fasano, J. B.: Local Heat Transfer in a Mixing Vessel Using Heat Flux Sensors. Ind. Eng. Chem. Res., Vol. 31, 1992, p. 1384-1391.

[4] Kresta, S. M., Wood, P. M.: The Mean Flow Field Produced by $a 45^{\circ}$ Pitched Blade Turbine: Changes in the Circulation Pattern Due to Off-bottom Clearance. Can. J. Chem. Eng., Vol. 71, 1993, p. 42-53.

[5] Winardi, S., Nagase, Y.: Unstable Phenomenon of Flow in a Mixing Vessel with a Marine Propeller. J. Chem. Eng. Japan, Vol. 24, 1991, p. 243-249.

[6] Brůha, O., Fořt, I., Smolka, P., Jahoda, M.: Experimental Study of Turbulent Macro-instabilities in an Agitated System with Axial High-speed Impeller and with Radial Baffles. Collect. Czech.Chem. Commun., Vol. 61, 1996, p. 856-867.

[7] Montes, J.-L., Boisson, H.-C., Fořt, I., Jahoda, M.: Velocity Field Macro-instabilities in an Axially Agitated Mixing Vessel. Chem. Eng. J., Vol. 67, 1997, p. 139-145.

[8] Guillard, F., Trägårdh, C., Fuchs, L.: New Image Analysis Methods for the Study of Mixing Patterns in Stirred Tanks. Can. J. Chem. Eng., Vol. 78, 2000, p. 273-285.

[9] Hasal, P., Montes, J.-L., Boisson, H.-C., Fořt, I.: Macro-instabilities of Velocity Field in Stirred Vessel: Detection and Analysis. Chem. Eng. Sci., Vol. 55, 2000, p. 391-401.

[10] Hasal, P., Forrt, I.: Macro-instabilities of the Flow Pattern in a Stirred Vessel: Detection and Characterization Using Local Velocity Data. Acta Polytechnica, Vol. 40, 2000, p. 55-67.
[11] Hasal, P., Kratěna, J., Fořt, I.: Frequency and Magnitude Analysis of the Macro-instability Related Component of the Tangential Force Affecting Radial Baffles in a Stirred Vessel. Acta Polytechnica, Vol. 42, 2002, p. 59-69.

[12] Kratěna, J., Fořt, I., Růžička, M., Brưha, O.: Analysis of Dynamic Stress Affecting a Radial Baffle in a Mechanically Agitated System. Acta Polytech., Vol. 39, 1999, p. 11-38.

[13] Kratěna, J., Fořt, I., Brůha, O., Pavel, J.: Distribution of Dynamic Pressure along a Radial Baffle in an Agitated System with Standard Rushton Turbine Impeller. Trans. IChemE, Vol. 79A, 2001, p. 819-823.

[14] Bittorf, K. J., Kresta, S. M.: Active Volume of Mean Circulation for Stirred Tanks Agitated with Axial Impellers. Chem. Eng. Sci., Vol. 55, 2000, p. 1325-1335.

[15] Yianneskis, M., Popiolek, Z., Whitelaw, J. H.: An Experimental Study of the Steady and Unsteady Flow Characteristics of Stirred Reactors. J. Fluid Mech., Vol. 175, 1987, p. 537-555.

[16] Montante, G., Lee, K. C., Brucato, A., Yianneskis, M.: Double to Single Loop Flow Pattern Transitions in Stirred Vessels. Can. J. Chem. Eng., Vol. 77, 1999, p. 649-659.

[17] Nikiforaki, L., Montante, G., Lee, K. C., Yianneskis, M.: On the Origin, Frequency and Magnitude of Macro-instabilities of the Flows in Stirred Vessels. Chem. Eng. Sci., Vol. 58, 2003, p. 2937-2949.

[18] Letellier, C., Le Sceller, L., Gousbet, G., Lusseyran, F., Kemoun, A., Izrar, B.: Recovering Deterministic Behavior from Experimental Time Series in Mixing Reactor. AlChE J., Vol. 43, 1997, p. 2194-2202.

[19] Kovacs, T., Trägårdh, C., Fuchs, L.: Fourier Spectrum to Recover Deterministic and Stochastic Behavior in Stirred Tanks. AIChE J., Vol. 47, 2001, p. 2167-2176.

[20] Lumley, J. L.: Stochastic Tools in Turbulence. New York: Academic Press, 1970.

[21] Aubry, N., Guyonnet, R., Lima, R.: Spatiotemporal Analysis of Complex Signals: Theory and Applications. J. Stat. Phys., Vol. 64, 1991, p. 683-739.

Doc. Ing. Pavel Hasal, CSc.

phone: +420224353167

fax: +420233337335

e-mail: Pavel.Hasal@vscht.cz

Department of Chemical Engineering \& Center for Nonlinear Dynamics of Chemical and Biological Systems Institute of Chemical Technology

Technická 5

16628 Prague 6, Czech Republic

Doc. Ing. Ivan Fořt, DrSc.

phone: +420224352713

fax: +420224310292

e-mail: fort@fsid.cvut.cz

Ing. Jiří Kratěna

e-mail: Jiri.Kratena@fs.cvut.cz

Czech Technical University in Prague

Faculty of Mechanical Engineering

Technická 4

16607 Prague 6, Czech Republic 